\title{
Meta-análisis \\ Eficacia cuestionable de la vacuna antineumocócica en adultos
}

Questionable efficacy of pneumococcal vaccine in adults

Huss y col. CMAJ 2009;180:48-58.

\section{Objetivo}

Evaluar la eficacia de la vacuna antineumocócica.

Fuente de datos, selección de estudios y extracción de datos MEDLINE, EMBASE, Cochrane CENTRAL, LILACS, InMed (Indian Medlars Centre), AIM (African Index Medicus) y referencias bibliográficas relacionadas, hasta 2007. Fueron incluidos ensayos aleatorizados o cuasi-aleatorizados* que hubieran comparado la vacuna polisacárida contra placebo, otras vacunas o ninguna intervención, sin restricción de idioma.

\section{Eventos de interés y análisis estadístico}

Neumonía por neumococo (presunta o con diagnóstico definitivo) y/o de cualquier etiología; bronquitis; mortalidad general por neumonía o por infección neumocócica; y enfermedad neumocócica invasiva o bacteriemia. Se analizó la heterogeneidad* entre los ensayos utilizando el índice $\mathbf{~}^{2}$. Para los resultados reportados por diez o más ensayos clínicos se estratifico el análisis de acuerdo a la calidad de los mismo, su entorno y su población.

\section{Resultados}

Fueron incluidos 22 ensayos que involucraron 101.507 participantes. La vacuna 23-valente fue utilizada en ocho ensayos. Los principales resultados se detallan en las tablas 1 y 2 .

La calidad de los ensayos (especialmente la referida a la condición de ceguera) explico una parte sustancial de la heterogeneidad entre los estudios que informaron neumonía presunta por neumococo y neumonía de cualquier etiología. Hubo pocas pruebas de la protección de la vacuna, aun entre los pacientes ancianos o adultos con enfermedades crónicas.

Tabla 1: Efectividad general de la vacuna antineumocócica

\begin{tabular}{l|c|c|c|c}
\multicolumn{1}{c|}{ Resultado } & Nro. Ensayos & Nro. de casos & RR (IC 95\%) & Heterogeneidad \\
\hline Neumonía presunta por neumococo & 11 & 589 & $0,64(0,43$ a 0,96$)$ & $\mathrm{I}^{2}=74 \%, \mathrm{p}<0,001$ \\
\hline Neumonía de cualquier etiología & 19 & 2.722 & $0,73(0,56$ a 0,94$)$ & $\mathrm{I}^{2}=90 \%, \mathrm{p}<0,001$ \\
\hline Mortalidad por neumonía & 8 & 214 & $0,88(0,62$ a 1,25$)$ & $\mathrm{I}^{2}=26 \%, \mathrm{p}<0,22$ \\
\hline Mortalidad por cualquier causa & 12 & 2.246 & $0,97(0,87$ a 1,09) & $\mathrm{I}^{2}=44 \%, \mathrm{p}=0,053$ \\
\hline
\end{tabular}

RR: Riesgo Relativo

Tabla 2: Efectividad de la vacuna antineumocócica en estudios de buena calidad metodológica, y en pacientes de riesgo

\begin{tabular}{|c|c|c|c|c|c|c|c|c|c|}
\hline \multirow{2}{*}{ Variable } & \multicolumn{3}{|c|}{ Neumonía presunta por neumococo } & \multicolumn{3}{|c|}{ Neumonia de cualquier etiologia } & \multicolumn{3}{|c|}{ Mortalidad por cualquier causa } \\
\hline & $\mathbf{N}$ & RR (IC 95\%) & $\mathbf{1}^{2}$ & N & RR (IC 95\%) & $\mathbf{I}^{2}$ & N & Heterogeneidad & $\mathbf{1}^{2}$ \\
\hline Ensayos doble ciego y controlados & 3 & $1,20(0,75$ a 1,92$)$ & 0 & 6 & $1,19(0,95$ a 1,49$)$ & 50 & 7 & $0,99(0,84$ a 1,17$)$ & 46 \\
\hline $\begin{array}{l}\text { Ensayos con adecuado } \\
\text { enmascaramiento de la asignación }\end{array}$ & 3 & $1,06(0,67$ a 1,67$)$ & 0 & 5 & $1,02(0,56$ a 1,21$)$ & 26 & 5 & $0,97(0,75$ a 1,24$)$ & 63 \\
\hline Pacientes de riesgo & 7 & $1,04(0,78$ a 1,38$)$ & 9 & 11 & $0,89(0,69$ a 1,14$)$ & 84 & 10 & $1,00(0,87$ a 1,14$)$ & 39 \\
\hline
\end{tabular}

RR: Riesgo Relativo. $I^{2}$ (\%): Heterogeneidad. N: número de estudios incluidos.

\section{Conclusiones}

A pesar de la gran heterogeneidad estadística existente entre los distintos ensayos en relación a la eficacia general de la vacuna antineumocócica, al restringir el análisis a los ensayos de mayor calidad la vacuna no parece ser efectiva en prevenir neumonías de cualquier tipo, bronquitis o disminuir la mortali- dad, ni siquiera en la población en la que está recomendada actualmente.

Palabras claves: vacunación neumococo, ensayo clínico aleatorizado. Key words: pneumococcal vaccination, randomized controled trial. Fuente de financiamiento: Organización Mundial de la Salud.

\section{Comentario}

La vacuna antineumocócica 23-valente, elaborada en base a antígenos polisacáridos purificados obtenidos de 23 serotipos de Streptococcus pneumoniae, está licenciada por la FDA desde 1982; siendo la complicación más temida por la infección de esta bacteria, la enfermedad neumocócica invasiva (ej. bacteriemia y meningitis).

Por otro lado, y de acuerdo a los datos argentinos de vigilancia continuada, alrededor del $90 \%$ de los serotipos aislados están representados en esta vacuna 1 .

En la actualidad la justificación en la indicación de la vacuna antineumocócica 23-valente, esta dirigida a la prevención de la enfermedad invasiva por S. Pneumoniae ${ }^{2,3}$, situación que se reflejó en pocos eventos en el presente trabajo (sólo 44 casos), lo cual restringe aquí su interpretación para esta indicación.

\section{Conclusiones del comentador}

Los resultados de esta investigación debilitan la evidencia que sustenta la indicación de vacunación antineumocócica con el objetivo de reducir la incidencia y la mortalidad asociada a la neumonía.

María de las Nieves Ganiele y Gabriel Villalón [ Senvicio de Medicina Familiar y Comunitaria del Hospital Italiano de Buenos Aires. maria.ganiele@hospitalitaliano.org.ar ] Recibido 21/11/2009 el y aceptado el 30/08/2010

Ganiele M. Eficacia cuestionable de la vacuna antineumocócica en los adultos. Evid Act Pract Ambul. 14.243 Abr-Jun 2011. Comentado de: Huss A y col. Efficacy of pneumococcal vaccination in adults: a meta-analysis. CMAJ 2009;180:48-58. PMID 19124790.

\section{Referencias}

1. Normas Nacionales de vacunación. Resolución 498/2008. Ministerio de Salud de la Nación. Disponible en URL http://www.femeba.org.ar/fundacion/quienessomos/Novedades/normas_nacionales_vacunacion_2008.pdf (ultimo acceso mayo 2011)

2. Toumanen E y col. Pneumococcal vaccination in adults. In: UpToDate, Basow, DS (Ed), UpToDate

Waltham, MA, 2010.

3. Nuorty J y col. (ACIP Pneumococcal Vaccines Working Group). Updated Recommendations for Prevention of Invasive Pneumococcal Disease Among Adults Using the 23-Valent Pneumococcal Polysaccharide Vaccine (PPSV23). National Center for Immunization and Respiratory Diseases, CDC. MMWR September 3, 2010;59(34):1102-06. 